\title{
Dynamics of Ascospore Release by Apiosporina morbosa from Sour Cherry Black Knots
}

\author{
W. McFadden-Smith, University of Guelph, Department of Plant Agriculture, Horticultural Research Institute of \\ Ontario, Box 7000, Vineland Station, Ontario, Canada L0R 2E0; J. Northover, Agriculture and Agri-Food Canada, \\ Box 6000, Vineland Station, Ontario, Canada L0R 2E0; and W. Sears, Ashton Statistical Laboratory, University of \\ Guelph, Guelph, Ontario, Canada N1G 2W1
}

\begin{abstract}
McFadden-Smith, W., Northover, J., and Sears, W. 2000. Dynamics of ascospore release by Apiosporina morbosa from sour cherry black knots. Plant Dis. 84:45-48.

Ascospore discharge was monitored from black knots excised from sour cherry trees in May 1992 and 1993, and March, April, and May 1994 and 1995. Rain, temperature, and wetness duration were monitored and a regression model was developed to describe the relationship between environmental conditions and ascospore discharge. Regardless of the date of excision, the peak period for ascospore release occurred from late May (shuck split) through the end of June (shoots $20 \mathrm{~cm}$ long), considerably later than previously reported from knots on plum. Fewer ascospores were released from knots excised in early March compared to later dates in 1994. In 1995, the spring was much warmer than in 1994 and ascospore release from Marchexcised knots was comparable to that from knots excised later in the spring. The period of release and total number of ascospores released was similar from non-excised knots and from knots excised in April or May 1994. Release of ascospores was dependent on rainfall and temperature, but not on the duration of wetness.
\end{abstract}

Additional keywords: Dibotryon morbosum, Prunus cerasus

Black knot is widely distributed on sour cherry (Prunus cerasus L.) in southern Ontario, Canada, and reduces production significantly in important sour cherrygrowing areas $(7,8)$. It is caused by the fungus Apiosporina morbosa (Schwein.:Fr.) Arx (= Dibotryon morbosum (Schwein.:Fr.) Theiss. \& Syd.). The disease causes girdling of small and medium-sized branches 1 or 2 years after infection. It is controlled by removing infected branches and knots from major limbs during normal dormant pruning of trees in late winter. These sanitation measures alone are seldom adequate and additional protective fungicide programs are essential. One of the goals of this study was to determine the best timing for fungicide applications based on the likelihood of infection by $A$. morbosum on sour cherry.

In 1992, the principal infection period in sour cherry at Jordan Station, Ontario oc-

Corresponding author: W. McFadden-Smith E-mail: wmcfadde@uoguelph.ca

Partial funding was provided by the Ontario Ministry of Agriculture, Food and Rural Affairs, Food Systems 2002, United Agri-Products, ISK BioSciences, Zeneca Agro, and D. W. Latter \& Associates.

Accepted for publication 10 September 1999.

Publication no. D-1999-1105-02R

(C) 2000 The American Phytopathological Society curred at the $10 \%$ shuck split stage, despite favorable weather conditions and inoculum availability in June and early July (8). This infection period was concurrent with a major ascospore release from excised knots $200 \mathrm{~m}$ away from the orchard. In southern Pennsylvania, ascospores were released from excised knots from plum trees $(P$. domestica cv. Stanley) from late April through late June, and most infections occurred after petal-fall during May and June (11). In contrast, maximum ascospore discharge from non-excised plum ( $P$. domestica cv. Stanley) knots occurred before petal fall in Michigan (9). Although Ritchie et al. (9) speculated that ascospores might be released earlier from non-excised than from excised knots, this hypothesis was not tested. With the exception of the recent report from Ontario (8), all previous studies of release of ascospores by A. morbosa have used knots from plum $(P$. domestica and $P$. salicina) or wild black cherry ( $P$. serotina; 3,9-11).

The objective of the present study was to examine the dynamics of ascospore release from sour cherry black knots with respect to environmental conditions and growth stage of sour cherry and use this information to optimize the timing of fungicide sprays.

\section{MATERIALS AND METHODS}

Ascospore discharge and associated environmental data. Well-developed knots, macroscopically free of fungal hyperpara- sites or insect damage, were cut from sour cherry trees ( $P$. cerasus cv. Montmorency) before bloom at Fonthill, Ontario on 9 May 1992 and on 20 April 1993 and at Jordan Station, Ontario on 7 March, 13 April, and 6 May 1994 and 15 March, 3 April, and 9 May 1995. A total of 11 and 19 knots were used in the 1992 and 1993 studies, respectively, and 15 knots were used for each excision date in 1994 and 1995. Ascospore discharge was monitored under field conditions for the following periods: 12 May to 22 July 1992, 28 April to 20 July 1993, 26 April to 29 July 1994, and 19 April to 1 August 1995. Each knot was mounted on a wooden dowel and a microscope slide (2.5 by $7.5 \mathrm{~cm}$ ) was supported horizontally immediately above the knot (8). The underside of the slide was coated with a mixture of cured petroleum jelly (75\%), paraffin wax $(21.4 \%)$ and toluene $(3.6 \%)$ to retain impacted ascospores and prevent them from germinating. Ascospore discharge was also monitored from 15 nonexcised knots remaining in the trees in 1994, to determine if the pattern of release of ascospores was similar to that of excised knots. After each rain, or after several days of dry weather, the slides were replaced. Slides were stained with lactophenol cotton blue and examined at 200 to $250 \times$ magnification. The number of ascospores per field was counted for each of 10 fields per slide and the number of ascospores per square centimeter was calculated. Temperature, rainfall, and wetness duration were monitored continuously throughout each growing season using a thermistor, tipping bucket rain gauge, and leaf wetness electrical impedance grid, respectively, and a Campbell 21X datalogger (Campbell Scientific Canada Corp., Edmonton, Alberta). The temperature sensor was housed in a radiation shield and located in the periphery of the orchard, the leaf wetness sensor was placed in the canopy of a tree, and the rain gauge was located adjacent to the orchard. The weather sensors were located approximately $200 \mathrm{~m}$ from the mounted excised knots used for the ascospore release studies.

Multiple regression analysis was used to determine the relationship between the number of ascospores trapped and rainfall, temperature during the rain period, and the duration of wetness commencing with rain. 
Data for the ascospore release periods in each year (from mid- to late May to early July) from 1992 through 1995 (total of 114 data points) were used in the regression analysis. Days with zero rainfall were not included in the model because, with a single exception, ascospore discharge did not occur without rain. Random effects (year and month of excision) were accounted for in the model. Some model building was done starting with a full second-order model, simplifying where indicated by the data. Residuals from the regression model were evaluated for normality and data were transformed with $\log _{10}(x+1)$ to satisfy assumptions of normality, to stabilize the variance, and to recognize that the effects were multiplicative rather than additive. Statistical analyses were performed with the MIXED procedure (1996; SAS Institute, Cary, NC).

In March 1995, before knots started to develop, several randomly selected limbs 1 to $1.7 \mathrm{~m}$ above the orchard floor were flagged on four unsprayed sour cherry trees in an orchard approximately $200 \mathrm{~m}$ from the ascospore collection site. The trees were examined weekly for the initial appearance of knots. In November 1995, after leaf drop, 300 shoots longer than $1 \mathrm{~cm}$ were examined on the flagged limbs on each tree and the distance of knots from the base of the shoots was recorded.

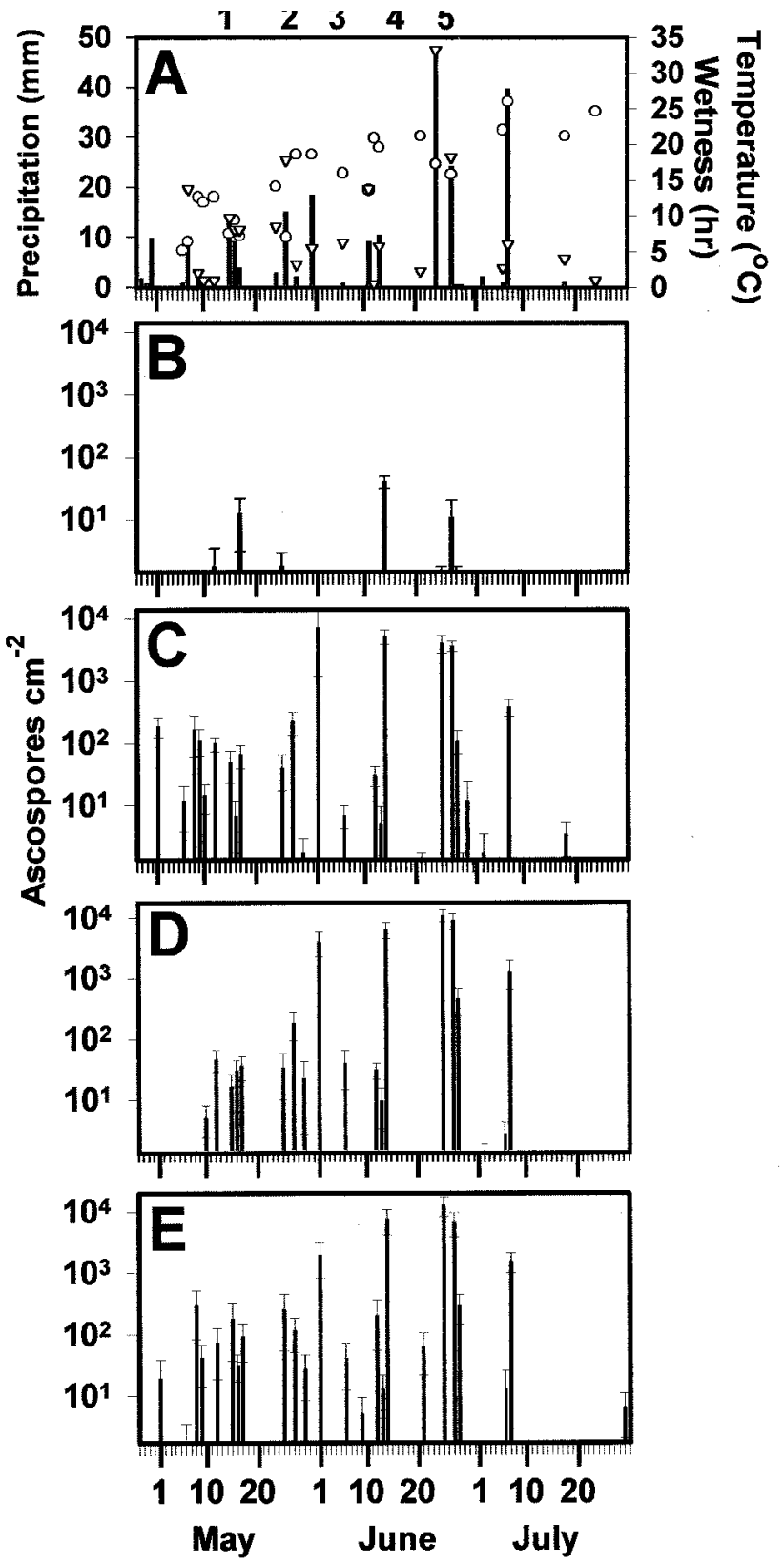

Fig. 1. (A) Relationship between precipitation (bars), temperature $(\bigcirc)$, and wetness duration $(\nabla)$ and ascospore discharge of Apiosporina morbosa from sour cherry black knots excised (B) 7 March, (C) 13 April, and (D) 6 May 1994, and (E) from non-excised knots. Phenological growth stages indicated on the top axis of plot A: 1 = full bloom (18 May); 2 = petal fall (27 May); $3=$ terminal shoots 5 to $10 \mathrm{~cm}$ (7 June); $4=$ terminal shoots $20 \mathrm{~cm}$ (16 June); and $5=$ terminal shoots $>25 \mathrm{~cm}$ (28 June).

\section{RESULTS}

Ascospore discharge and associated environmental data. Ascospores were released from knots as early as 28 April (pre-bloom) and as late as 14 July (terminals > $25 \mathrm{~cm}$ long; Figs. 1 and 2). The major period for release of ascospores from all knots in all years was from late May (petal fall to shuck split) through midto late June (shoots $20 \mathrm{~cm}$ long) (Table 1). Knots excised in March 1994 produced significantly fewer ascospores than those excised in April and May 1994. Nonexcised knots released comparable numbers of ascospores to knots excised in April or May 1994. Knots excised in March 1995 released more ascospores than those excised in March 1994. Fewer ascospores were released from knots excised in April and May 1995 than in the previous years.

The spring of 1995 was considerably warmer than that of 1994. Degree day (DD) accumulation (base $5^{\circ} \mathrm{C}$ ) started much earlier in 1995, with comparable DD accumulations at the 15 March 1995 (26 DD) and the 13 April 1994 (27.5 DD) excision dates (Table 1).

Multiple regression of ascospore release against rainfall $(\mathrm{mm})$, temperature $\left({ }^{\circ} \mathrm{C}\right)$, and wetness duration (h) was described by the model: $\log \left(\right.$ ascospores $\left.\mathrm{cm}^{-2}+1\right)=$ $-4.775+0.325$ (rain) +0.763 (temperature) $-0.0047\left(\right.$ rain $\left.^{2}\right)-0.023$ (temperature $\left.{ }^{2}\right)+$ 0.032 (wetness) $\left(r^{2}=0.77\right)$. Standard errors and $P$ values for terms in the multiple regression model are presented in Table 2 . The relationship of ascospore release to rainfall and temperature based on the regression equation is presented graphically in Figure 3. The model indicates that there was a rather steep initial increase in the number of ascospores released with increasing volumes of rain, but the rate of increase tapered off with higher amounts of rain. A similar relationship was evident between ascospore release and temperature. The effect of wetness duration on ascospore release was not significant in the model $(P=0.48)$. According to the model, maximum ascospore discharge occurred with $30 \mathrm{~mm}$ rain at $17^{\circ} \mathrm{C}$.

At least $0.25 \mathrm{~mm}$ of rain was required to stimulate ascospore discharge, with the exception of a release during 9 to 16 June 1995. In this rare situation, rain $(2.5 \mathrm{~mm})$ occurred on 3 June, slides were replaced on 9 June, and the next occurrence of rain was 25 June. Dew periods of $11 \mathrm{~h}$ (9 to 10 June), $8 \mathrm{~h}$ (10 to 11 June), and $9 \mathrm{~h}$ (13 to 14 June) occurred during this period. Relatively large numbers of ascospores (mean 350 ascospores $\mathrm{cm}^{-2}$ ) were detected on most slides collected on 16 June.

No swellings were visible on shoots examined monthly from November 1994 to April 1995. The first symptoms of infection (light brown swellings with epidermis starting to split) were identified on 15 May, when trees were in full bloom, and new knots continued to be found until mid- 
June. The frequency of knots on unsprayed trees with respect to distance from the shoot base was: at the base, $9.8 \% ; 1$ to 10 $\mathrm{cm}, 22.6 \%$; 11 to $20 \mathrm{~cm}, 22.3 \% ; 21$ to 30 $\mathrm{cm}, 22.0 \%$; 31 to $40 \mathrm{~cm}, 18.4 \%$; and over $40 \mathrm{~cm}, 4.8 \%$.

\section{DISCUSSION}

This study significantly expands on our earlier reports $(5,8)$ of ascospore release from black knots of sour cherry; collectively, the reports provide the most complete data set available to describe this epidemiological phenomenon, and have important implications with respect to the implementation of sanitation procedures. Furthermore, this is the first report to document disease progress on sour cherry, a host of black knot that has not been extensively investigated previously.

Over the 4 years of this study, the earliest ascospore release from knots from sour cherry was detected pre-bloom and the latest occurred well after terminal growth had ceased and just prior to fruit maturity. Peak ascospore release occurred from late May through mid- or late June, varying with the year, at sour cherry growth stages from shuck split through the end of shoot growth and fruit maturity.

There appear to be differences in the physiological interaction between $A$. morbosa and its different hosts. On plum ( $P$. domestica), some black knot infections develop as small swellings within four months of infection (4), while on sour cherry, initial symptoms do not appear until bloom of the year following infection (8). Ascospores were released from sour cherry knots later in the season and peak release occurred over a longer period of time in our study than previously reported for plum knots $(3,9-11)$. Plum trees become active earlier in the growing season, with bud break and bloom generally 1 to 2 weeks earlier than in sour cherries. There may be some degree of synchrony between the physiological activity of the host and ascospore maturity and release of the pathogen.

In 1994, ascospore discharge was very limited from knots excised in early March, whereas discharge from knots excised in
April and May was similar to non-excised knots. These findings are similar to those of Koch (3), who found that pseudothecia on knots on $P$. domestica discharged more spores when knots were collected after the end of March than if collected earlier. It is possible that the knots excised in March 1994 were still dependent on factors in the host tissue necessary for pseudothecia to mature. In contrast, there was no difference in the release of ascospores between knots excised in March and April 1995. This probably occurred because the maturation process started earlier in the year due to the warm spring conditions as shown by the earlier accumulation of degree days (Table

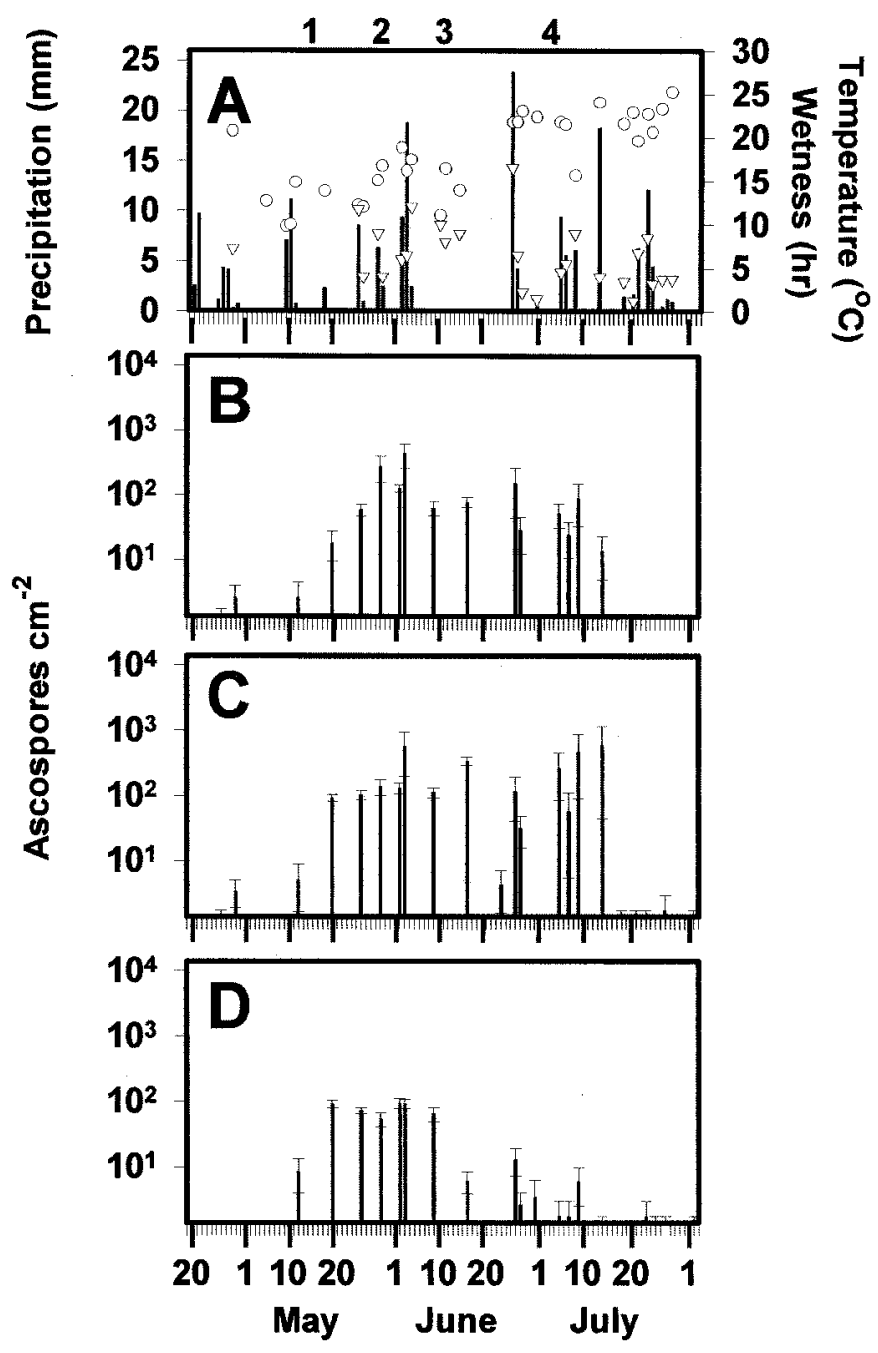

Fig. 2. (A) Relationship between precipitation (bars), temperature $(\bigcirc)$, and wetness duration $(\nabla)$ and ascospore discharge of Apiosporina morbosa from sour cherry black knots excised (B) 15 March, (C) 3 April, and (D) 9 May 1995. Phenological growth stages indicated on the top axis of plot A: $1=$ full bloom (15 May); 2 = petal fall (29 May); $3=$ terminal shoots 5 to $10 \mathrm{~cm}$ (12 June); and $4=$ terminal shoots $>25 \mathrm{~cm}$ ( 3 July).

Table 1. Cumulative degree days at knot excision, mean seasonal total of ascospores released per knot, peak period of ascospore release, and phenological growth stage, 1992 to 1995

\begin{tabular}{|c|c|c|c|c|c|}
\hline \multicolumn{3}{|c|}{ Time of knot excision } & \multirow[b]{2}{*}{ Mean seasonal total per knot $\left(\operatorname{ascospores} \mathbf{c m}^{-2}\right)^{a}$} & \multicolumn{2}{|c|}{ Period of peak ascospore release } \\
\hline Year & Date & Degree days (base $5^{\circ} \mathrm{C}$ ) & & Date & Growth stage $^{\mathrm{b}}$ \\
\hline 1992 & 9 May & 108.1 & $2.5 \times 10^{4}$ & 30 May-24 June & Shuck split \\
\hline 1993 & 3 May & 91.8 & $9.8 \times 10^{4}$ & 23 May-26 June & Petal fall \\
\hline \multirow[t]{4}{*}{1994} & 7 March & 0 & $7.0 \times 10^{1}$ & 13 June & Shuck fall \\
\hline & 13 April & 27.5 & $4.1 \times 10^{4}$ & 31 May-14 June & Shuck fall \\
\hline & 6 May & 127.9 & $3.3 \times 10^{4}$ & 31 May-14 June & Shuck fall \\
\hline & non-excised & & $3.5 \times 10^{4}$ & 31 May-14 June & Shuck fall \\
\hline \multirow[t]{3}{*}{1995} & 15 March & 26 & $1.4 \times 10^{3}$ & 29 May-25 June & Petal fall \\
\hline & 3 April & 44.2 & $3.1 \times 10^{3}$ & 29 May-25 June & Petal fall \\
\hline & 9 May & 130.4 & $5.2 \times 10^{2}$ & 29 May-25 June & Petal fall \\
\hline
\end{tabular}

a Numbers of knots included for ascospore release study: 1992, 11 knots; 1993, 19 knots; 1994 and 1995, 15 knots for each excision date.

b Through shoots $>25 \mathrm{~cm}$, except 13 June 1994. 
Table 2. Estimates, standard errors, and $P$ values for effects in multiple regression model describing the relationship between ascospore release and rainfall, temperature, and wetness duration ${ }^{\mathrm{a}}$

\begin{tabular}{lccr}
\hline Effect & Estimate & Standard error & P value \\
\hline Intercept & -4.775 & 1.689 & 0.007 \\
Rain (slope) & 0.325 & 0.058 & $<0.001$ \\
Temperature (slope) & 0.763 & 0.236 & 0.001 \\
Wetness duration & 0.032 & 0.045 & 0.476 \\
Rain $\times$ rain (slope) & -0.0047 & 0.001 & $<0.001$ \\
Temperature $\times$ temperature & -0.023 & 0.008 & 0.004 \\
\hline
\end{tabular}

${ }^{\mathrm{a}} R^{2}=0.77(P<0.05)$

1). Despite this early start to the maturation process, the total ascospore release in 1995 was only $10 \%$ of that in 1994 . The variability in peak ascospore production among years may be a contributing factor to the sporadic nature of black knot outbreaks observed in commercial orchards (11).

Our findings and those of others $(3,9,11)$ of the prolonged release of ascospores from excised knots emphasize the importance of removing and destroying as many knots as possible from infected trees to reduce the amount of ascosporic inoculum. Knots excised in March, 5 to 6 weeks prior to bloom, were capable of maturing and releasing ascospores for up to 4 months after they were removed from the tree, and therefore must be completely removed from the orchard floor. All knot removal should be completed before the new shoots that develop in late bloom, are exposed to infection. Brush piles should be burned to completely eradicate knots.

The number of ascospores released and the duration of release were similar from non-excised knots and those excised in April 1994. This suggests that the speculation of Ritchie et al. (9), that the date of maximum ascospore discharge from plum ( $P$. domestica) knots may be determined by whether or not the inoculum source is nonexcised or excised knots, may not apply to sour cherry. Our results show that, for experiments with sour cherry, late-excised knots or non-excised knots should be equally suitable as inoculum sources in studies of host infectivity or fungicide performance.

Large ascospore releases from sour cherry knots followed precipitation of at least $10 \mathrm{~mm}$ and a temperature of at least $11^{\circ} \mathrm{C}$. These findings are similar to the earlier reports on sour cherry (8) and on plum (11). Maximum ascospore release occurred at $17^{\circ} \mathrm{C}$ and, at any given temperature, ascospore discharge increased with increasing amounts of rainfall as described by the regression model. Koch (3) identified a similar trend for ascospore release from continuously wet pseudothecia on excised plum knots, with negligible release at 0 to $2^{\circ} \mathrm{C}$, light at 3 to $5^{\circ} \mathrm{C}$, very heavy at 10 to $27^{\circ} \mathrm{C}$, and negligible at $31^{\circ} \mathrm{C}$.
The ascospore discharge that occurred from 9 to 16 June 1995 was unusual in that it took place 6 to 13 days after $2.5 \mathrm{~mm}$ of rain on 3 June. Ascospore release from knots from plum $(3,4,9,11)$ or sour cherry (8) has not been reported previously in the absence of rain under orchard conditions. Three wetting periods ( 8 to $11 \mathrm{~h}$ each), associated with dew, occurred between 9 and 16 June, and were believed to have induced ascospore discharge.

The relationship of ascospore discharge to wetting has been studied in a number of stromatal species of Pyrenomycetes $(1,2,6)$. Most of the fungi in these studies required wetting in the form of a minimum amount of rainfall to initiate ascospore release, and a saturated atmosphere alone did not induce discharge. However, in Mycosphaerella pinoides, ascospore liberation from perithecia on pea straw depended on wetting but release could be induced by dew alone (1). While the majority of ascospore releases by $A$. morbosa required rainfall of at least $0.25 \mathrm{~mm}$, under rare circumstances ascospores appear to have been released in response to dew periods alone.

While the time of ascospore release occurred during the same period of growth of the sour cherry host, the time of infection, as evidenced by the location of the knot on the shoots, was variable. In 1994, the knots on non-fungicide-treated trees were located with equal frequency from the shoot base to over $40 \mathrm{~cm}$ from the base of infected shoots. This differs from our 1992 results (8), where most knots occurred 1 to $2 \mathrm{~cm}$ from the base of the shoot, and supports the hypothesis that infections occurred significantly later and over a longer period of time in 1994 than in 1992. The need for fungicide protection cannot be predicted solely on the basis of when peak ascospore releases occur. However, a season-long fungicide program with compounds that are active against black knot and other diseases of sour cherry, including brown rot (Monilinia fructicola (G. Wint.) Honey), powdery mildew (Podosphaera clandestina (Wallr.:Fr.) Lév.), and leaf spot (Blumeriella jaapii (Rehm) Arx), will provide integrated control of these diseases.

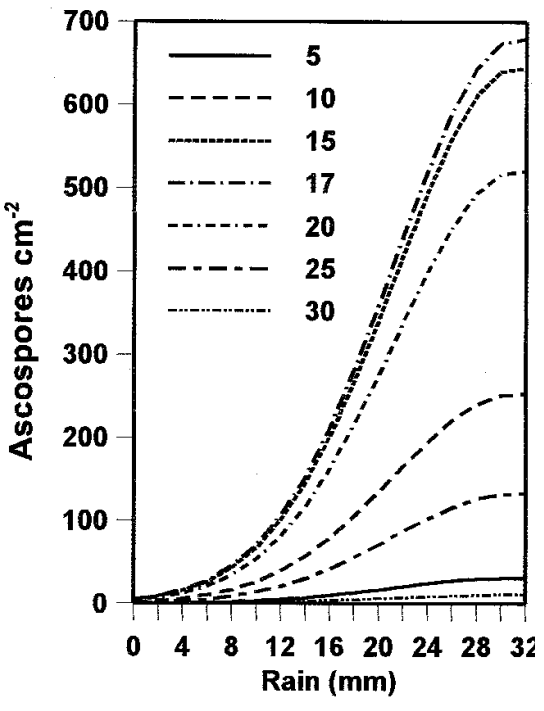

Fig. 3. Relationship between release of Apiosporina morbosa ascospore release from knots on sour cherry and rainfall at different temperatures, as determined by the model, $\log \left(\right.$ ascospores $\left.\mathrm{cm}^{-2}+1\right)=-4.683+0.313$ $($ rain $)+0.762$ (temperature) $-0.005\left(\right.$ rain $\left.^{2}\right)-$ 0.023 (temperature $\left.^{2}\right)+0.032$ (wetness).

\section{ACKNOWLEDGMENTS}

We thank J. Martin, K. Schneider, L. Fursey, D. Kerec, and A. Myers for technical assistance.

\section{LITERATURE CITED}

1. Carter, M. V. 1963. Mycosphaerella pinoides. II.. The phenology of ascospore release. Aust. J. Agric. Res. 16:800-817.

2. Gruenhagen, R. E. 1945. Hypoxylon pruinatum and its pathogenesis on poplar. Phytopathology 35:72-89.

3. Koch, L. W. 1933. Investigations on black knot of plums and cherries. I. Development and discharge of spores and experiments in control. Sci. Agric. 13:576-590.

4. Koch, L. W. 1935. Investigations on black knot of plums and cherries. IV. Studies in pathogenicity and pathological histology. Sci. Agric. 15:729-743.

5. McFadden-Smith, W., and Northover, J. 1997. Epidemiology of black knot of sour cherry. Phytopathology 87:S64.

6. Moller, W. J., and Carter, M. V. 1965. Production and dispersal of ascospores in Eutypa armeniacae. Aust. J. Biol. Sci. 18:67-80.

7. Northover, J., and McFadden-Smith, W. 1994. Fungicides control black knot of sour cherry. Can. Fruitgrower April, 1994. p. 8

8. Northover, J., and McFadden-Smith., W 1995. Control and epidemiology of Apiosporina morbosa of sour cherry and plum. Can. J. Plant Pathol. 17:57-68

9. Ritchie, D. F., Klos, E. J., and Yoder, K. S.. 1975. Epidemiology of black knot of 'Stanley' plums and its control with systemic fungicides. Plant Dis. Rep. 59:499-503

10. Smith, D. H. 1966. A study of certain aspects of the black knot diseases of plum and its causal agent, Dibotryon morbosum (Schw.) Theiss. \& Syd. Ph.D. dissertation, Penn State University.

11. Smith, D. H., Lewis, F. H., and Wainwright, S. H. 1970. Epidemiology of the black knot disease of plums. Phytopathology 60:14411441 . 